This is an author produced version of a paper published in Phytochemistry.

This paper has been peer-reviewed and is proof-corrected, but does not include the journal pagination.

Citation for the published paper:

Glinwood, Robert; Ninkovic Velemir; Pettersson, Jan. (2011) Chemical interaction between undamaged plants - Effects on herbivores and natural enemies. Phytochemistry. Volume: 72, Number: 13, pp 1683-1689. http://dx.doi.org/10.1016/j.phytochem.2011.02.010.

Access to the published version may require journal subscription. Published with permission from: Elsevier.

Epsilon Open Archive http://epsilon.slu.se 


\title{
Chemical interaction between undamaged plants- effects on herbivores and natural enemies
}

Robert Glinwood*, Velemir Ninkovic, Jan Pettersson

Department of Ecology, Swedish University of Agricultural Sciences, 752 Uppsala, Sweden

\begin{abstract}
Most research on plant-plant chemical interactions has focussed on events following herbivore or pathogen attack. However, undamaged plants also interact chemically as a natural facet of their behaviour, and this may have consequences for insects that use the plants as hosts. In this review, the links between allelopathy and insect behaviour are outlined. Findings on how chemical interactions between different plant species and genotypes affect aphid herbivores and their natural enemies are reviewed, and the role of plant diversity and chemical interaction for trophic interactions in crops is discussed.
\end{abstract}

Keywords: Allelobiosis; Allelopathy; Tritrophic interaction; Aphids; Ladybirds

*Corresponding author. E-mail address: robert.glinwood@slu.se tel.: +46 18672342; fax: +4618672890 


\section{Contents}

1. Introduction

2. Linking allelopathy and plant-insect interaction

3. Interactions between different plant species and effects on insects

3.1. Effects on aphids

3.2. Effects on aphid natural enemies

4. Interactions between genotypes of the same plant species and effects on insects

4.1 Effects on aphids

4.2. Effects on aphid natural enemies

5. Discussion

6. Conclusions

Acknowledgements

References 


\section{Introduction}

Plants and insects use chemical information to solve many of the challenges they face. It has been known for a long time that insects use chemical cues from plants and from conspecifics, however it took longer for biologists to accept that plants may also detect and use chemical cues. Over the last two decades, knowledge on plant-plant chemical signalling has advanced rapidly, revealing how herbivore-induced volatiles from one plant can induce responses in neighbouring undamaged plants that deter herbivores and attract their natural enemies (Arimura et al., 2000; Bruin et al., 1992; Dicke, 2009). Recent studies suggest these volatiles may also represent a rapid, within-plant signalling mechanism (Frost et al., 2007; Heil and Bueno, 2007).

However, plants release chemicals even when they are not attacked by herbivores or pathogens, and these can play important roles in plant behaviour and interactions. Release of volatile organic compounds can help plants acclimatize to abiotic stress, contributing to thermotolerance (Sharkey and Yeh, 2001) and the removal of reactive oxygen species (Loreto and Velikova, 2001), and there is a growing appreciation that chemical emissions may have wider importance for plant biology (Holopainen, 2004). For example, it has been discovered that volatiles produced by leaves may be used as host location cues by parasitic plants; a fascinating parallel to the way herbivorous insects use the same compounds (Runyon et al., 2006).

Attack by herbivores and pathogens can initiate substantial changes in plant volatile emission that may either be transitory or more persistent due to priming. Although infestation and infection are frequently observed in nature and clearly merit high priority responses from the plant, we argue that, with the exception of outbreaks and epidemics, the most important challenge a plant 
individual is likely to face comes from its continuous interaction with neighbouring plants. Thus, while it is unclear to what extent 'undamaged' plants truly exist in nature, we use the term to refer to underlying conditions rather than those specifically related to attack.

This review describes how chemicals released by undamaged plants can affect neighbouring plants and influence interactions with herbivores and natural enemies. We begin with an appraisal of the links between allelopathy and insect behaviour, and define the term 'allelobiosis' to describe these interactions. We then discuss our own research on interactions between weeds, different barley genotypes, aphids and ladybirds that has opened a new perspective on plant-plant chemical communication.

\section{Linking allelopathy and plant-insect interaction}

It is surprising that more attention has not been paid to the wider ecological impact of chemical interactions between undamaged plants, since it has been known for centuries that plants can interact in this way. The process was named allelopathy by (Molisch, 1937) and is defined as 'the positive or negative effect of one plant on another through chemicals that escape into the environment' (Rice, 1984). Several hundred allelopathic plant chemicals that affect growth and physiology of receiving plants have been identified, and studies have demonstrated their modes of action (Field et al., 2006; Hierro and Callaway, 2003). Allelopathy has been seen almost exclusively as a form of chemical warfare with only negative consequences for the exposed individual, even though Rice (1984) acknowledged in his classical definition that allelopathy could have positive effects on the receiving plant. For example, chemicals released by undamaged plants may have informational value for neighbouring individuals (Kegge and Pierik, 2010; Ninkovic, 2010). Plants of one barley 
cultivar changed their pattern of biomass allocation after exposure to volatiles from a neighbouring plant of a different cultivar (Ninkovic, 2003), and the behaviour of aphid herbivores and their natural enemies was also affected.

These findings led us to employ the term 'allelobiosis' to describe the wider trophic effects of allelopathy (Ninkovic et al., 2006) (summarised in Fig. 1). The three key aspects of allelobiosis are (i) the chemicals are not released specifically in response to herbivore or pathogen attack, but as part of the plant's underlying metabolism, (ii) the receiving plant may benefit from exposure and (iii) the receiving plant's response to exposure affects insect herbivores and their natural enemies. Our aim in coining this term was not to challenge the established definition of allelopathy, but rather (a) to draw attention to the fact that chemical exchange between undamaged plants may have biological effects beyond those on the receiving plant, which has not been widely addressed, (b) to have a concise term to describe these interactions without the need to repeat the above definition and (c) as a framework that can be used to stimulate and test new ideas on plant-plant interaction.

The effects of allelopathy on other trophic levels have not been explored extensively, however there is limited evidence indirectly linking allelopathy and herbivory (Fig. 2). For example, herbivory has been shown to influence a plant's allelopathic potential. Root herbivory on the invasive plant Centaurea maculosa increased exudation of the flavanol $( \pm)$-catechin, an allelopathic agent that negatively affects other plant species (Thelen et al., 2005). However, herbivory by a phloem-feeding aphid reduced the allelopathic activity of the weed Ageratum conyzoides (Kong et al., 2002). There are examples of compounds known to be allelopathic agents in plant-plant interactions that directly repel or deter herbivores (Bouda et al., 2001), a classic example being caffeine (Kim et al., 2006). Allelopathic phenolics in the leaves of the 
invasive shrub Lonicera maackii deterred feeding by lepidopteran larvae, with the flavone apigenin as the potential active compound (Cipollini et al., 2008).

Conversely, compounds known to affect the behaviour of insect herbivores, such as the sesquiterpenes (E)- $\beta$-farnesene and $\beta$-caryophyllene (Beale et al., 2006; Mayer et al., 2008), also have allelopathic activity (Kong et al., 2004; Wang et al., 2009). Methyl salicylate, the volatile ester of the plant hormone salicylic acid, is often found among the volatiles released by plants in response to herbivory (Dicke and Hilker, 2003), and has been shown to enhance the allelopathic activity of exposed rice plants (Bi et al., 2007). Methyl salicylate is a known plant defence inducer and has been used successfully in the field to protect cereal crops against pest aphids (Ninkovic et al., 2003; Pettersson et al., 1994; Prinsloo et al., 2007), but it is not known whether stimulation of the host plants' allelopathic potential was involved.

A major source of volatiles produced independently of stress or damage is floral scent. Although floral compounds clearly serve as attractants for pollinators, it has been argued that, in evolutionary terms, they were originally involved in other aspects of plant behaviour such as defence (Heil, 2008), so it interesting to speculate on their possible role in plant-plant interactions. Volatiles from flowers of snapdragon, Antirrhinum majus, have been shown to inhibit growth of Arabidopsis roots, with the volatile ester methyl benzoate found to be mainly responsible (Horiuchi et al., 2007). This compound also induced expression of Arabidopsis genes related to germination and growth. Investigation of the wider roles of floral volatiles, including plantplant interaction, is needed.

Volatiles from sagebrush, Artemisia tridentata, have been shown both to inhibit seed germination in neighbouring plants (Karban, 2007) and to reduce herbivory in exposed plants (Karban et al., 2006), although it is not known whether the same volatile cues are responsible 
for both effects. Although not an allelopathic interaction, studies on hemiparasitic plants have demonstrated how transfer of chemicals from one plant to another can affect plant-insect interactions such as herbivory and pollination (Adler et al., 2001). Finally, chemicals released by one plant may be passively absorbed by a neighbour leading to associational resistance. For example, ledene, ledol and palustrol released by birch were absorbed on leaves of neighbouring rhododendron and subsequently affected its herbivores (Himanen et al., 2010). Despite the evidence for indirect links between allelopathy and herbivory, and even though attempts have been made to model the effects of allelopathy on communities (Blanco, 2007), the potential of allelopathy to affect trophic interactions via changes in the status of receiving plants has been almost completely overlooked. We now review our findings on chemical interaction between undamaged plants, dealing separately with chemical interactions between different plant species and between different genotypes of the same species and discussing the consequences for plant interaction with aphid herbivores and their natural enemies.

\section{Interactions between different plant species and effects on insects}

Plant species diversity has been linked to the diversity and abundance of insect herbivores and natural enemies (Haddad et al., 2001), and attempts to manipulate it have been made using mixed species intercropping in agricultural systems. This led to several hypotheses linking plant diversity and tritrophic interactions (Andow, 1991; Root, 1973; Russell, 1989) that have been partly supported by studies in crop and natural systems (Andow, 1991; Haddad et al., 2001; Koricheva et al., 2000). Although chemical interaction between plant species has been mentioned in theories seeking to explain these findings (Bandara et al., 2009; Thiery and Visser, 1987; Uvah and Coaker, 1984), it is surprising that this mechanism has not been more widely discussed, particularly since many plant species are known to be allelopathic. 


\subsection{Effects on aphids}

Work in our laboratory has shown that direct chemical interaction between weeds and crop plants can affect insects that use the plants as hosts. Barley plants exposed to root exudates from the couch grass, Elytrigia repens, became less acceptable for the bird cherry-oat aphid Rhopalosiphum padi, a serious pest of cereals (Glinwood et al., 2003). A mixture of four chemicals previously identified as root exudates from the weed, hydroxytryptophan, hydroxytryptophan hydrate, indolacetic acid and a carboline (6-hydroxy-1,2,3,4-tetrahydro- $\beta$ -carboline-3-carboxylic acid) (Hagin, 1989; Hagin and Bobnick, 1991) reduced aphid acceptance of barley when applied in solution to the soil around the plant. In contrast to the examples in Fig. 2 C, the substances themselves did not repel or deter feeding by the aphid, rather they appeared to cause changes in the receiving barley plants that made them less attractive for the aphid. The rhizosphere is populated by a range of microorganisms, often associated with plant roots, which may be pathogenic or symbiotic. These organisms can modify allelopathic chemicals released from plant roots and contribute novel substances from their own metabolism (Inderjit and van der Putten, 2010), creating a microbial 'black box' that is difficult to fully predict. Advances in the techniques for isolating and identifying soil microorganisms will hopefully lead to better understanding of their role in plant-plant chemical interactions.

Allelobiosis also occurs via aerial interaction, presumed to be mediated by plant volatile organic compounds. Barley plants exposed for several days to volatiles from the thistle Cirsium vulgare became less acceptable to cereal aphids (Glinwood et al., 2004). Barley exposed to volatiles from the weed Chenopodium album had reduced aphid settling in the laboratory and also in the field when the weed was sown alongside barley in mixed plots 
(Ninkovic et al., 2009). However, the same study demonstrated that the effects of weed volatiles on barley is limited to certain species and is not likely to occur ubiquitously throughout the plant kingdom. Recently it has been shown that the presence of competitive weed species can induce increased levels of the hydroxamic acid 2,4-dihydroxy-7-methoxy1,4-benzoxazin-3-one (DIMBOA) in wheat plants (Zheng et al., 2010). Although it is not clear to what extent hydroxamic acids affect aphid-plant interactions (Bravo et al., 2004; Nicol and Wratten, 1997), this type of induction could potentially alter interactions of the exposed plants with a range of insects and with neighbouring plants.

\subsection{Effects on aphid natural enemies}

Direct volatile interactions between certain weeds and barley also affect aphid natural enemies. The seven spot ladybird Coccinella septempunctata is an important aphid predator commonly found in barley fields (Hodek and Michaud, 2008). Despite the importance of aphids in its diet, it feeds on a range of insects and other food sources. In a barley crop in which aphids were not present in significant numbers, ladybird occurrence was significantly higher in patches containing either the couch grass E. repens or the thistle Cirsium arvense than in weedless patches (Ninkovic and Pettersson, 2003). Plant biomass was similar in the different patches and the weeds were not flowering. Supporting laboratory studies showed that, although odour of neither weed was directly attractive to ladybirds, the mixed odours of barley and E. repens were more attractive than that of barley alone, suggesting that increasing odour diversity can trigger attraction or arrestment in this predator. Further, the odour of barley previously exposed to volatiles from $C$. arvense was more attractive to ladybirds than was odour of unexposed plants (Ninkovic and Pettersson, 2003). 


\section{Interactions between genotypes of the same plant species and effects on insects}

Most research on the role of plant biodiversity for trophic interactions has focussed on diversity between different plant species, and has overlooked the idea that diversity between different genotypes of the same plant species may have ecological relevance. Crop plants, in which breeding has created different genotypes with known pedigrees, are good models for the study of intra-specific plant diversity. Indeed, mixing different genotypes of the same species of crop plant has been shown to reduce the incidence of several damage-causing organisms that use the plants as hosts (Cadet et al., 2007; Mundt, 2002; Power, 1991). It is not known to what extent chemical interactions can explain these findings, however our own research has established that volatile chemical interaction between different barley genotypes affects both aphids and their natural enemies, and this work will be discussed next.

\subsection{Effects on aphids}

When four barley cultivars were exposed to volatiles from each other in a pair wise design, exposed plants became significantly less acceptable to the aphid $R$. padi in certain combinations (Ninkovic et al., 2002; Pettersson et al., 1999). The findings have been supported by subsequent studies that have identified a range of genotype combinations that give this effect (Glinwood et al., 2009; Kellner et al., 2010; Ninkovic and Åhman, 2009). A screening program with hundreds of barley genotype combinations revealed interesting patterns. For example, certain genotypes act most often as inducers whereas others act most often as responders. Older genotypes (i.e. released to the market longer ago) have a greater tendency to respond to volatile exposure, whereas more recent ones are more likely to be inducers (Kellner et al., 2010). Genotypes that supported lower aphid growth also showed the 
ability to respond to volatile exposure from a particular different genotype with reduced aphid acceptance (Ninkovic and Åhman, 2009).

These findings have led to interest in exploiting barley genotype interactions for management of aphid pests in the field. For example, certain genotype combinations that gave reduced aphid acceptance after volatile exposure in the laboratory also had reduced aphid acceptance when grown together in 1:1 mixtures in the field (Ninkovic et al., 2002) (Fig. 3). Although interactions in the field are likely to be complex, with potential for competition and underground chemical exchange, this raises the question of whether volatile interactions between barley genotypes can affect aphid behaviour within field crops. This is interesting because mixed cultivar cropping in cereals has been shown to reduce the incidence of fungal pathogens and aphid-borne plant viruses (Mundt, 2002; Power, 1991), and mixing plant genotypes can reduce biotic damage and increase yields (Cadet et al., 2007; Gustafsson, 1953; Tratwal et al., 2007)

\subsection{Effects on aphid natural enemies}

Plant diversity arising from combining different genotypes of the same plant species has generally been assumed to weakly influence the third trophic level (Johnson and Agrawal, 2005). Evidence for effects of within species genotype diversity on higher trophic levels in natural ecosystems has been reported (Johnson, 2008), however its expected impact may be greater in crop systems than in natural ones because, against the very homogenous genetic background of agricultural monocrops, genetic diversity within the plant species may be more apparent. 
Allelobiosis between different barley genotypes affects not only aphids but also the behaviour of their natural enemies. In a spring barley crop, significantly more adult seven spot ladybirds C. septempunctata were recorded in plots sown with a 1:1 ratio of two different barley cultivars than in pure plots of either cultivar alone (Ninkovic et al., 2010). Laboratory experiments suggest that both direct and indirect volatile chemical interaction between the cultivars may be involved since, in certain combinations of barley cultivars, ladybirds are attracted both to odour of one cultivar exposed to another as well as the combined odours of two different cultivars (Glinwood et al., 2009; Ninkovic et al., 2010).

\section{Discussion}

The findings discussed above illustrate how chemical interactions between undamaged plants can affect plant-insect interaction. A major question in understanding the adaptive significance of these effects is whether to focus on their importance for plant responses to herbivores or plant responses to other plants? The greatest challenge faced by plants can arguably be said to arise, not from attack by herbivores or pathogens, but from interaction from neighbouring plants. During their evolution, plants have developed behaviours to resist or respond to competition from other plants (Trewavas, 2009), and they can use information from their environment, including chemical signals, in deploying these behaviours (Izaguirre et al., 2006; Kegge and Pierik, 2010; Novoplansky, 2009). Since neighbouring plants are likely to compete for resources, it should benefit a plant to be able to detect the presence of a potential competitor in advance and respond in an appropriate way (Broz et al., 2010; Ninkovic, 2010). 
Evidence for self-recognition and kin-recognition in plants is accumulating (Biedrzycki and Bais, 2010), with focus mainly on rhizosphere processes mediated by the root system (Dudley and File, 2007). Since plants are known to use chemical cues from neighbouring plants in relation to defence induction, exchange of chemicals should be a primary potential route for both self- and kin-recognition. Although this theory has not yet been tested extensively, recent studies provide evidence for recognition via chemical exchange both below ground (Biedrzycki et al., 2010) and above ground (Karban and Shiojiri, 2009). Plant behaviour in response to recognition of non-self, neighbours or kin is expected to relate to avoidance or adaptation to competition and may involve changes in patterns of growth or physiology. The extent to which this may affect individual insects or insect communities associated with the plant is still unknown, but effects on higher trophic levels can be predicted, especially for insects that are highly adapted to particular host plants and are sensitive to host quality.

This would include aphids, which are very sensitive to changes in host plant status (Pettersson et al., 2007). Laboratory studies with different barley cultivars found that the pattern of biomass allocation changed in response to exposure to volatiles from undamaged neighbouring plants (Ninkovic, 2003). Plants exposed to volatiles from a different cultivar allocated more biomass to roots and less to shoots and leaves than plants exposed to volatiles from the same cultivar, or to air alone. The total biomass of exposed plants did not differ significantly suggesting a reallocation of available resources that may signify a competitive response to detection of a neighbour. The responding cultivar in that study also had reduced aphid acceptance after exposure to volatiles from the emitting neighbour (Glinwood et al., 2007; Ninkovic et al., 2002; Pettersson et al., 1999) indicating a possible link between plant neighbour detection and effects on plant-insect interaction. 
These effects may extend to the third trophic level, illustrated by attraction of the ladybird $C$. septempunctata to odour of barley exposed to different genotypes. It is possible that olfactory cues from exposed plants, and those from mixtures of barley genotypes, trigger recognition of botanical diversity. Although aphids are a vital food for C. septempunctata, it is a polyphagous predator and should benefit from botanically diverse habitats, particularly when aphids are scarce (Pettersson et al., 2005). This ladybird is known to make extensive use of volatile chemical cues in locating habitats, plants and prey (Pettersson et al., 2008). Although being able to detect mixtures of barley genotypes may not be directly advantageous to the ladybird, the findings reviewed here suggest that odour cues associated with plant-plant chemical interaction and odour mixing and could potentially be used as cues denoting habitats or patches with enhanced plant diversity.

A question arising from the findings reviewed here is whether they can be exploited for management of aphids in crops? Mixed cultivation of carefully selected barley genotypes to reduce aphid incidence may have potential, particularly if the relevant characteristics can be identified and made available to plant breeding programs ( $\AA$ hman et al., 2010; Åhman and Ninkovic, 2010). If the chemical cues mediating the biological interactions are identified, these could be applied as formulations that modify plant or insect behaviour. Although current knowledge is mainly limited to a model system with barley, there is evidence from other agricultural systems that mixing different genotypes of the same plant species can affect organisms that use the plants as hosts (Cadet et al., 2007; Mundt, 2002; Power, 1991). These questions may become more relevant in the future. For example, a trend in certain regions of the world is the gradual phasing out of chemical pesticides. This may increase the likelihood of interaction between crops and weeds. Thus, understanding the role of chemical interactions 
in shaping the behaviour of insect pests and their predators in crops will be increasingly valuable.

\section{Conclusions}

We are beginning to appreciate chemical interaction between plants as a natural facet of their behaviour that does not only take place when they are attacked by herbivores or pathogens. However, our understanding of ecological implications of undamaged plant-plant interaction and its effects on herbivores and their predators is minimal when compared to the advances made in the mechanistic and evolutionary understanding of damaged-induced signalling. Nevertheless, the findings reviewed here demonstrate that chemical interactions between undamaged plants can have consequences for insects at higher trophic levels. We have defined the term allelobiosis to describe these interactions, with the aim of stimulating discussion and further research on this topic. Since chemical exchange between plant neighbours can potentially occur in any habitat, increased understanding of the consequences of allelopathy and related processes not just for plants but for insects could be valuable for fields as varied as biodiversity, invasion biology and sustainable crop production.

\section{Acknowledgements}

R. Glinwood, V. Ninkovic and J. Pettersson were funded by by Mistra through the PlantComMistra program and the Swedish Research Council for Environment, Agricultural Sciences and Spatial Planning (Formas). 


\section{References}

Adler, L. S., Karban, R., Strauss, S. Y., 2001. Direct and indirect effects of alkaloids on plant fitness via herbivory and pollination. Ecology 82, 2032-2044.

Åhman, I., Glinwood, R., Ninkovic, V., 2010. The potential for modifying plant volatile composition to enhance resistance to arthropod pests. CAB Reviews: Perspectives in Agriculture, Veterinary Science, Nutrition and Natural Resources 5, 10 pp.

Åhman, I., Ninkovic, V., 2010. Volatile interactions between undamaged plants: effects and potential for breeding resistance to aphids. In: Baluska, F., Ninkovic, V. (Eds.), Communication from an Ecological Perspective. Springer-Verlag, Berlin, pp. 113-125. Andow, D. A., 1991. Vegetational diversity and arthropod population response. Annu. Rev. Ecol. Syst. 36, 561-586.

Arimura, G., Ozawa, R., Shimoda, T., Nishioka, T., Boland, W., Takabayashi, J., 2000. Herbivory-induced volatiles elicit defence genes in lima bean leaves. Nature 406, 512-515. Bandara, K., Kumar, V., Ninkovic, V., Ahmed, E., Pettersson, J., Glinwood, R., 2009. Can leek interfere with bean plant-bean fly interaction? Test of ecological pest management in mixed cropping. J. Econ. Entomol. 102, 999-1008.

Beale, M. H., Birkett, M. A., Bruce, T. J. A., Chamberlain, K., Field, L. M., Huttly, A. K., Martin, J. L., Parker, R., Phillips, A. L., Pickett, J. A., Prosser, I. M., Shewry, P. R., Smart, L. E., Wadhams, L. J., Woodcock, C. M., Zhang, Y. H., 2006. Aphid alarm pheromone produced by transgenic plants affects aphid and parasitoid behavior. Proc. Natl. Acad. Sci. U. S. A. 103, 10509-10513.

Bi, H., Zeng, R., Su, L., An, M., Luo, S., 2007. Rice allelopathy induced by methyl jasmonate and methyl salicylate. J. Chem. Ecol. 33, 1089-1103. 
Biedrzycki, M. L., Bais, H. P., 2010. Kin recognition in plants: a mysterious behaviour unsolved. J. Exp. Bot. 61, 4123-4128.

Biedrzycki, M. L., Jilany, T. A., Dudley, S. A., Bais, H. P., 2010. Root exudates mediate kin recognition in plants. Communicative and Integrative Biology 3, 28-35.

Blanco, J. A., 2007. The representation of allelopathy in ecosystem-level forest models. Ecol. Model. 209, 65-77.

Bouda, H., Tapondjou, L. A., Fontem, D. A., Gumedzoe, M. Y. D., 2001. Effect of essential oils from leaves of Ageratum conyzoides, Lantana camara and Chromolaena odorata on the mortality of Sitophilus zeamais (Coleoptera, Curculionidae). J. Stored Prod. Res. 37, 103-109. Bravo, H. R., Copaja, S. V., Argandona, V. H., 2004. Chemical basis for the antifeedant activity of natural hydroxamic acids and related compounds. J. Agric. Food Chem. 52, 25982601.

Broz, A. K., Broeckling, C. D., De-La-Pena, C., Lewis, M. R., Greene, E., Callaway, R. M., Sumner, L. W., Vivanco, J. M., 2010. Plant neighbor identity influences plant biochemistry and physiology related to defense. BMC Plant Biol. 10, 14.

Bruin, J., Dicke, M., Sabelis, M. W., 1992. Plants are better protected against spider-mites after exposure to volatiles from infested conspecifics. Experientia 48, 525-529.

Cadet, P., Berry, S. D., Leslie, G. W., Spaull, V. W., 2007. Management of nematodes and a stalk borer by increasing within-field sugarcane cultivar diversity. Plant. Pathol. 56, 526-535. Cipollini, D., Stevenson, R., Enright, S., Eyles, A., Bonello, P., 2008. Phenolic metabolites in leaves of the invasive shrub, Lonicera maackii, and their potential phytotoxic and antiherbivore effects. J. Chem. Ecol. 34, 144-152.

Dicke, M., 2009. Behavioural and community ecology of plants that cry for help. Plant Cell Environ. 32, 654-665. 
Dicke, M., Hilker, M., 2003. Induced plant defences: from molecular biology to evolutionary ecology. Basic Appl. Ecol. 4, 3-14.

Dudley, S. A., File, A. L., 2007. Kin recognition in an annual plant. Biology Letters 3, 435438.

Field, B., Jordan, F., Osbourn, A., 2006. First encounters - deployment of defence-related natural products by plants. New Phytol. 172, 193-207.

Frost, C. J., Appel, M., Carlson, J. E., De Moraes, C. M., Mescher, M. C., Schultz, J. C., 2007. Within-plant signalling via volatiles overcomes vascular constraints on systemic signalling and primes responses against herbivores. Ecol. Lett. 10, 490-498.

Glinwood, R., Ahmed, E., Qvarfordt, E., Ninkovic, V., Pettersson, J., 2009. Airborne interactions between undamaged plants of different cultivars affect insect herbivores and natural enemies. Arthropod-Plant Interact. 3, 215-224.

Glinwood, R., Gradin, T., Karpinska, B., Ahmed, E., Jonsson, L. M. V., Ninkovic, V., 2007. Aphid acceptance of barley exposed to volatile phytochemicals differs between plants exposed in daylight and darkness. Plant Signalling and Behavior, 205-210.

Glinwood, R., Ninkovic, V., Pettersson, J., Ahmed, E., 2004. Barley exposed to aerial allelopathy from thistles (Cirsium spp.) becomes less acceptable to aphids. Ecol. Entomol. 29, 188-195.

Glinwood, R., Pettersson, J., Ahmed, E., Ninkovic, V., Birkett, M., Pickett, J., 2003. Change in acceptability of barley plants to aphids after exposure to allelochemicals from couch-grass (Elytrigia repens). J. Chem. Ecol. 29, 261-274.

Gustafsson, Å., 1953. The cooperation of genotypes in barley. Hereditas 39, 1-18. Haddad, N. M., Tilman, D., Haarstad, J., Ritchie, M., Knops, J. M. H., 2001. Contrasting effects of plant richness and composition on insect communities: A field experiment. Am. Nat. 158, 17-35. 
Hagin, R. D., 1989. Isolation and identification of 5-hydroxyindole-3-acetic acid and 5hydroxytryptophan, major allelopathic aglycons in quackgrass (Agropyron repens L Beauv). J. Agric. Food Chem. 37, 1143-1149.

Hagin, R. D., Bobnick, S. J., 1991. Isolation and identification of a slug-specific molluscicide from quackgrass (Agropyron repens, L Beauv). J. Agric. Food Chem. 39, 192-196.

Heil, M., 2008. Indirect defence- recent developments and open questions. In: Luttke, W., Beyschlag, W., Murata, J. (Eds.), Prog. Bot., vol. 69. Springer, Berlin, pp. 360-395.

Heil, M., Bueno, J. C. S., 2007. Within-plant signaling by volatiles leads to induction and priming of an indirect plant defense in nature. Proc. Natl. Acad. Sci. U. S. A. 104, 5467-5472. Hierro, J. L., Callaway, R. M., 2003. Allelopathy and exotic plant invasion. Plant Soil 256, 29-39.

Himanen, S. J., Blande, J. D., Klemola, T., Pulkkinen, J., Heijari, J., Holopainen, J. K., 2010. Birch (Betula spp.) leaves adsorb and re-release volatiles specific to neighbouring plants - a mechanism for associational herbivore resistance? New Phytol. 186, 722-732. Hodek, I., Michaud, J. P., 2008. Why is Coccinella septempunctata so successful? (A pointof-view). Eur. J. Entomol. 105, 1-12.

Holopainen, J. K., 2004. Multiple functions of inducible plant volatiles. Trends Ecol. Evol. 9, $529-533$.

Horiuchi, J., Badri, D. V., Kimball, B. A., Negre, F., Dudareva, N., Paschke, M. W., Vivanco, J. M., 2007. The floral volatile, methyl benzoate, from snapdragon (Antirrhinum majus) triggers phytotoxic effects in Arabidopsis thaliana. Planta 226, 1-10.

Inderjit, van der Putten, W. H., 2010. Impacts of soil microbial communities on exotic plant invasions. Trends Ecol. Evol. 25, 512-519. 
Izaguirre, M. M., Mazza, C. A., Biondini, M., Baldwin, I. T., Ballare, C. L., 2006. Remote sensing of future competitors: Impacts on plant defenses. Proc. Natl. Acad. Sci. U. S. A. 103, $7170-7174$

Johnson, M. T. J., 2008. Bottom-up effects of plant genotype on aphids, ants, and predators. Ecology 89, 145-154.

Johnson, M. T. J., Agrawal, A. A., 2005. Plant genotype and environment interact to shape a diverse arthropod community on evening primrose (Oenothera biennis). Ecology 86, 874-885. Karban, R., 2007. Experimental clipping of sagebrush inhibits seed germination of neighbours. Ecol. Lett. 10, 791-797.

Karban, R., Shiojiri, K., 2009. Self-recognition affects plant communication and defense. Ecol. Lett. 12, 502-506.

Karban, R., Shiojiri, K., Huntzinger, M., McCall, A. C., 2006. Damage-induced resistance in sagebrush: Volatiles are key to intra- and interplant communication. Ecology 87, 922-930. Kegge, W., Pierik, R., 2010. Biogenic volatile organic compounds and plant competition. Trends Plant Sci. 15, 126-132.

Kellner, M., Kolodinska Brantestam, A., Åhman, I., Ninkovic, V., 2010. Plant volatileinduced aphid resistance in barley cultivars is related to cultivar age. Theor. Appl. Genet. 121, 1133-1139.

Kim, Y. S., Uefuji, H., Ogita, S., Sano, H., 2006. Transgenic tobacco plants producing caffeine: a potential new strategy for insect pest control. Transgenic Res. 15, 667-672. Kong, C. H., Hu, F., Liang, W. J., Peng, W., Jiang, Y., 2004. Allelopathic potential of Ageratum conyzoides at various growth stages in different habitats. Allelopathy J. 13, 233240.

Kong, C. H., Hu, F., Xu, X. H., 2002. Allelopathic potential and chemical constituents of volatiles from Ageratum conyzoides under stress. J. Chem. Ecol. 28, 1173-1182. 
Koricheva, J., Mulder, C. P. H., Schmid, B., Joshi, J., Huss-Danell, K., 2000. Numerical responses of different trophic groups of invertebrates to manipulations of plant diversity in grasslands. Oecologia 125, 271-282.

Loreto, F., Velikova, V., 2001. Isoprene produced by leaves protects the photosynthetic apparatus against ozone damage, quenches ozone products, and reduces lipid peroxidation of cellular membranes. Plant Physiol. 127, 1781-1787.

Mayer, C. J., Vilcinskas, A., Gross, J., 2008. Pathogen-induced release of plant allomone manipulates vector insect behavior. J. Chem. Ecol. 34, 1518-1522.

Molisch, H., 1937. Der Einfluss einer Pflanze auf die andere-Allelopathie. Gustav Fischer, Jena.

Mundt, C. C., 2002. Use of multiline cultivars and cultivar mixtures for disease management. Annu. Rev. Phytopathol. 40, 381-410.

Nicol, D., Wratten, S. D., 1997. The effect of hydroxamic acid concentration at late growth stages of wheat on the performance of the aphid Sitobion avenae. Ann. Appl. Biol. 130, 387396.

Ninkovic, V., 2003. Volatile communication between barley plants affects biomass allocation. J. Exp. Bot. 54, 1931-1939.

Ninkovic, V., 2010. Volatile interaction between undamaged plants: a short cut to coexistence. In: Baluska, F., Ninkovic, V. (Eds.), Communication from an ecological perspective. Springer-Verlag, Berlin, pp. 75-86.

Ninkovic, V., Åhman, I. M., 2009. Aphid acceptance of Hordeum genotypes is affected by plant volatile exposure and is correlated with aphid growth. Euphytica 169, 177-185. Ninkovic, V., Ahmed, E., Glinwood, R., Pettersson, J., 2003. Effects of two types of semiochemical on population development of the bird cherry oat aphid Rhopalosiphum padi in a barley crop. Agric. Forest Entomol. 5, 27-33. 
Ninkovic, V., Al Abassi, S., Ahmed, E., Glinwood, R., Pettersson, J., 2010. Effect of withinspecies plant genotype mixing on habitat preference of a polyphagous insect predator. Oecologia DOI 10.1007/s00442-010-1839-2.

Ninkovic, V., Glinwood, R., Dahlin, I., 2009. Weed-barley interactions affect plant acceptance by aphids in laboratory and field experiments. Entomol. Exp. Appl. 133, 38-45. Ninkovic, V., Glinwood, R., Pettersson, J., 2006. Communication between undamaged plants by volatiles: the role of allelobiosis. In: Baluska, F., Mancuso, S., Volkmann, D. (Eds.), Communication in Plants: Neuronal Aspects of Plant Life. Springer-Verlag, Berlin, pp. 421434.

Ninkovic, V., Olsson, U., Pettersson, J., 2002. Mixing barley cultivars affects aphid host plant acceptance in field experiments. Entomol. Exp. Appl. 102, 177-182.

Ninkovic, V., Pettersson, J., 2003. Searching behaviour of the sevenspotted ladybird, Coccinella septempunctata - effects of plant-plant odour interaction. Oikos 100, 65-70. Novoplansky, A., 2009. Picking battles wisely: plant behaviour under competition. Plant Cell Environ. 32, 726-741.

Pettersson, J., Ninkovic, V., Ahmed, E., 1999. Volatiles from different barley cultivars affect aphid acceptance of neighbouring plants. Acta Agric. Scand. Section B, Soil Plant Sci. 49, $152-157$.

Pettersson, J., Ninkovic, V., Glinwood, R., Al Abassi, S., Birkett, M., Pickett, J., Wadhams, L., 2008. Chemical stimuli supporting foraging behaviour of Coccinella septempunctata L. (Coleoptera: Coccinellidae): volatiles and allelobiosis. Appl. Entomol. Zool. 43, 315-321. Pettersson, J., Ninkovic, V., Glinwood, R., Birkett, M. A., Pickett, J. A., 2005. Foraging in a complex environment - semiochemicals support searching behaviour of the seven spot ladybird. Eur. J. Entomol. 102, 365-370. 
Pettersson, J., Pickett, J. A., Pye, B. J., Quiroz, A., Smart, L. E., Wadhams, L. J., Woodcock, C. M., 1994. Winter host component reduces colonization by bird-cherry oat aphid, Rhopalosiphum padi (L) (Homoptera, Aphididae), and other aphids in cereal fields. J. Chem. Ecol. 20, 2565-2574.

Pettersson, J., Tjallingii, W. F., Hardie, J., 2007. Host Plant Selection and Feeding. In: van Emden, H. F., Harrington, R. (Eds.), Aphids as Crop Pests. CABI, UK, pp. 87-107.

Power, A. G., 1991. Virus spread and vector dynamics in genetically diverse plant-populations. Ecology 72, 232-241.

Prinsloo, G., Ninkovic, V., Linde, T. C. v. d., Westhuizen, A. J. v. d., Pettersson, J., Glinwood, R., 2007. Test of semiochemicals and a resistant wheat variety for Russian wheat aphid management in South Africa. J. Appl. Entomol. 131, 637-644.

Rice, E., 1984. Allelopathy, 2nd edn. Academic Press, New York.

Root, R. B., 1973. Organization of a plant-arthropod association in simple and diverse habitats: the fauna of collards (Brassica oleracea). Ecol. Monogr. 43, 95-124.

Runyon, J. B., Mescher, M. C., Moraes, C. M. d., 2006. Volatile chemical cues guide host location and host selection by parasitic plants. Science 313, 1964-1967.

Russell, E. P., 1989. Enemies hypothesis: a review of the effect of vegetational diversity on predatory insects and parasitoids. Environ. Entomol. 18, 590-599.

Sharkey, T. D., Yeh, S. S., 2001. Isoprene emission from plants. Annu. Rev. Plant Physiol. Plant Mol. Biol. 52, 407-436.

Thelen, G. C., Vivanco, J. M., Newingham, B., Good, W., Bais, H. P., Landres, P., Caesar, A., Callaway, R. M., 2005. Insect herbivory stimulates allelopathic exudation by an invasive plant and the suppression of natives. Ecol. Lett. 8, 209-217.

Thiery, D., Visser, J. H., 1987. Misleading the colorado potato beetle with an odor blend. J. Chem. Ecol. 13, 1139-1146. 
Tratwal, A., Law, J., Philpott, H., Horwell, A., Garner, J., 2007. The possibilities of reduction of winter barley chemical protection by growing variety mixtures. Part II. Effect on yield. J. Plant Prot. Res. 47, 79-86.

Trewavas, A., 2009. What is plant behaviour? Plant Cell Environ. 32, 606-616.

Uvah, III, Coaker, T. H., 1984. Effect of mixed cropping on some insect pests of carrots and onions. Entomol. Exp. Appl. 36, 159-167.

Wang, R. L., Peng, S. L., Zeng, R. S., Ding, L. W., Xu, Z. F., 2009. Cloning, expression and wounding induction of beta-caryophyllene synthase gene from Mikania micrantha HBK and allelopathic potential of beta-caryophyllene. Allelopathy J. 24, 35-44.

Zheng, Y. Q., Liu, X. G., Dong, F. S., Li, J., Gong, Y., Zhu, G. Y., 2010. Biological induction of DIMBOA in wheat seedlings by weeds. Allelopathy J. 25, 433-440. 
Figure 1. Chemical interactions between undamaged plants can affect the behaviour of herbivores and their natural enemies on exposed plants directly via volatile chemical cues (dotted lines) and indirectly via changes in host quality (bold lines).

Figure 2. Interactions linking allelopathy and insect behavior:
A) Herbivory influences production of allelopathic substances (Thelen et al., 2005; Kong et al., 2002).
B) Chemical inducers enhance production of allelopathic substances (Bi et al., 2007).
C) Chemical compounds have both allelopathic and insect behavioural activity (Bouda et al., 2001; Kong et al., 2004; Kim et al., 2006; Cippollini et al., 2008; Wang et al., 2009).
D) Plants exposed to allelopathy become less attractive to herbivores (Ninkovic et al., 2002; Åhman et al., 2009; Kellner et al., 2010; Himanen et al. 2010).

E) Plants exposed to allelopathy become more attractive to herbivore natural enemies (Ninkovic et al., 2003; Glinwood et al., 2009).

Figure 3. Aphid plant acceptance of barley cultivar Kara after exposure to volatiles from certain other barley cultivars in laboratory studies and growing together with certain other barley cultivars in a field experiment $(* \mathrm{P}<0.05)$ (data from Ninkovic et al., 2002). 